\title{
Об опыте разработки «Градостроительного атласа России» и современном использовании его результатов
}

\author{
Е.Л.Беляева, 000 «ИГБИ», Москва
}

В 1991-1994 годах по заданию Минстроя России «Институт геобиосферных исследований $\mathrm{PAEH»} \mathrm{разрабатывал}$ «Градостроительный атлас России» (М 1:8 000 000). В статье с точки зрения научной значимости и возможности современного использования дана оценка выполненных работ. Целью разработки атласа являлось обобщение самой современной на тот период информации о территории России, её оценки с позиций расселения и градостроительства, а задачами систематизация, анализ и прогноз. Атлас был призван стать символом научного престижа отрасли, предназначался для широкого применения в проектировании, управлении, при обучении специалистов градостроительных специальностей.

Работа выполнялась в начале «перестройки», в период максимальной открытости информации, интенсивного межотраслевого сотрудничества министерств, ведомств, специалистов различных областей науки, заинтересованных в комплексной оценке территорий страны, её регионов и городов. Это было предпосылкой новизны и уникальности полученных результатов.

В работе над «Градостроительным атласом России» приняли участие ведущие специалисты в области градостроительства, географии, экологии, геологии, экономики и других научных дисциплин. На начальном этапе были разработаны методология, методика, структура, содержание атласа и ряда тематических карт, их предполагалось около 50. К концу 1993 года было разработано 15 карт, пробным тиражом изданы две - посвящённые наиболее актуальным проблемам того времени («Радиационная обстановка России» и «Транспорт России. Основные коммуникации»). Несмотря на прекрасные отзывы специалистов и организаций в период кризиса в 1994 году работы были приостановлены и впоследствии не возобновлялись.

Сегодня, когда в соответствии с «майскими» указами Президента России В.В.Путина наступило время активных действий в сфере обоснований стратегического планирования пространственного развития и практического решения актуальных задач расселения и градостроительства, целесообразно использовать наработки «Градостроительного атласа России», в том числе в области методологии. Методология создания атласа в определённой степени является прообразом формирования будущих отраслевых информационных систем, использующих методы электронного картографирования.

Значительная часть разработанных карт не потеряла своей актуальности или требует небольшой актуализации, после чего они смогут стать составной частью аналитической базы пространственного развития.
Ключевые слова: Градостроительный атлас России (М 1:8 000 000), методология разработки, междисциплинарные исследования, современное использование, отраслевые информационные системы.

On the Experience of Developing the "Urban Development Atlas of Russia" and the Modern Use of its Results

E.L.Belyaeva, 000 "IGBI", Moscow

In 1991-1994, on the instructions of the Ministry of Construction of Russia, the Institute of Geobiosphere Studies of the Russian Academy of Natural Sciences developed the Urban Development Atlas of Russia (Scale 1:8 000 000). The article assesses the work performed in terms of scientific significance and the possibility of modern use. The purpose of developing the Atlas as a collection of maps of a single scale, united by a common approach - focus on sustainable development, was to summarize the most up-to-date information on the territory of Russia from the perspective of resettlement and urban planning, and the tasks were to systematize, analyze and forecast it. The Atlas was intended to become a symbol of the scientific prestige of the industry, intended for widespread use in the design, management, and training of specialists in urban planning specialties.

The work was carried out at the beginning of the "perestroika", during the period of maximum transparency of information, intensive intersectoral cooperation of ministries, departments, specialists of various fields of science interested in a comprehensive assessment of the country's territories, its regions, and cities. This was a prerequisite for the novelty and uniqueness of the results.

Leading experts in the field of urban planning, geography, ecology, geology, economics, and other scientific disciplines took part in the work on the "Urban Planning Atlas of Russia". At the initial stage, a methodology, structure, content of the atlas and several thematic maps were developed ( 50 were supposed). By the end of 1993, 15 maps had been developed, with a trial run published two devoted to the most pressing problems of that time ("Radiation Situation in Russia" and "Transport of Russia. Basic Communications"). Despite the excellent reviews of specialists and organizations, during the crisis in 1994 work was suspended and subsequently did not resume.

Today, when, in accordance with the "May" Decrees of the President of the Russian Federation, V. Putin, the time has come for active actions in the field of strategic planning of spatial development of Russia, scientific substantiation and 
practical solution of urgent problems of resettlement and urban development, it is advisable to use the achievements of the Urban Development Atlas. The Atlas creation methodology is a prototype of the formation of future industry information systems using electronic mapping and urban cadaster methods.

A significant part of the developed maps has not lost its relevance or requirelittle updating, after which they can become an important part of the analytical base of spatial development.

Keywords: Urban Development Atlas of Russia (Scale 1:8 000000 ), development methodology, interdisciplinary research, modern use, industry information systems.

\section{История создания «Градостроительного атласа России» и его научное значение}

Планирование пространственного развития России с её изменчивыми природно-климатическими и ландшафтными условиями, урботехногенным и ресурсным потенциалом, с различиями народно-хозяйственной специализации регионов и городов, различной плотностью населения, транспортной сети и инженерной инфраструктуры, с различным уровнем развития агломерационных процессов должно опираться на междисциплинарную информационно-аналитическую научную базу и использовать современные инструменты комплексной оценки и прогнозирования развития территории в области расселения и градостроительства.

После принятия в 2014 году Федерального закона от 28.06.2014 № 172-03 «0 стратегическом планировании в Российской Федерации» ${ }^{1}$ в качестве приоритетного направления фундаментальных исследований Российская академия архитектуры и строительных наук (РАACH) разрабатывает научные основы пространственного развития России на основе концепции устойчивого развития регионов и городов. Авторским коллективом под руководством академика Г.В. Есаулова был разработан и опубликован проект документа «Градостроительная доктрина Российской Федерации» [1], который предваряли более ранние материалы и публикации, подготовленные по линии РАACH [2-4].

Значительных комплексных исследований и проектов, обосновывающих градостроительную политику и пространственное развитие России на «макроуровне» в последующий период не проводилось. Выполненные и опубликованные работы в основном ограничились исследованием агломерационныхпроцессов. Углублённые исследования выполнены для некоторых проектов и схем объектов территориального планирования, для обоснования концепций регионов опережающего развития и генпланов городов (Москва, Московская область, Урал, Краснодарский край, Ростовская область, Дальний Восток).

\footnotetext{
${ }^{1}$ Федеральный закон от 28 июня 2014 г. № 172-Ф3 «0 стратегическом планировании в Российской Федерации» (с изменениями и дополнениями) [Электронный ресурс] // Информационно-правовой портал «Гарант.ру». Режим доступа: http://ivo.garant.ru/\#/document/70684666/paragraph/5:0 (дата обращения 27.09.2019).
}

Таким образом, «Градостроительный атлас России», разработка которого началась в 90-е годы, - в первые годы «перестройки» является последним крупным научным исследованием в области комплексной оценки территории России для целей планирования, расселения и градостроительства.

Работы по «Градостроительному атласу России», выполнялись «Институтом геобиосферных исследований» (000 «ИГБИ») Российской академии естественных наук по заданию Минстроя России в 1991-1994 годах, они не были завершены, однако полученные результаты безусловно имеют фундаментальное значение и в наше время представляют значительный научный и практический интерес. Более того, актуальность их использования повышается в связи с задачами разработки «Концепции пространственного развития России».

В своё время создание «Градостроительного атласа России» было тесно связано с разработкой «Генеральной схемы расселения на территории России» (Минстрой России, «Гипрогор», 1991-1993 гг., руководитель А.И. Мелик-Пашаев). В этом крупнейшем проекте были использованы наработки «Градостроительного атласа России». «Институт геобиосферных исследований» выполнил обосновывающий раздел генсхемы - «0ценка состояния окружающей среды методами картирования», что стало хорошей апробацией материалов атласа и подтвердило практическую значимость выполняемой научной работы.

Интересна история практического применения методов картографии в градостроительстве. В 60-80 годах прошлого века отдельные тематические карты по оценке территории России уже получили достаточно широкое распространение в градостроительной науке и практике. Карты использовались в СНиПах, ГОСТах, методических указаниях по проектированию. Если в справочнике проектировщика «Градостроительство», изданном в 1963 году [5], приведены только две карты (климатические), то в справочнике проектировщика «Районная планировка» (1986) приводится около десяти карт [6]. Наряду с комплексной картой «Районирование территории СССР по природным условиям для целей градостроительства», даны пофакторные карты климата, сейсмического районирования, распространения неблагоприятных инженерно-геологических процессов (карстов, селей, оползней), другие виды карт.

В 1970-1980-х годах в теории и практики градостроительства произошёл прорыв в область экологии - важнейшего фактора устойчивого развития страны. Особенно значимыми стали исследования расселения и градостроительства, которые опирались на первый опыт междисциплинарного анализа экологических проблем, разработки ТерКСоПов городов и областей (В.В. Владимиров, С.Б. Чистякова) [7; 8]. В качестве инструмента сравнительной оценки территорий, выявления проблемных ситуаций, разработки градостроительных прогнозов в ТерКСОПах всегда использовалось картирование различного масштаба. В то время развитие градостроительных систем различного уровня, в том числе макро- и мезоуровня, стали связывать с задачами формирования «экологического 
каркаса расселения» (В.В. Владимиров, С.Б. Чистякова и другие). В градостроительной деятельности, в том числе в «Генеральной схеме расселения СССР (ЦНИИП Градостроительства, 1984), широко использовались достижения географии (физической, экономической и социальной), экономики и народно-хозяйственного планирования, геоэкологии, гидрологии, гигиены и других областей и оценки, выполненные методами картирования.

Таким образом, к началу работ над «Градостроительным атласом России» в градостроительной науке и практике уже был накоплен значительный опыт градостроительной оценки территорий с использованием карт и схем различного масштаба и появилась возможность его развивать с учётом достижений смежных научных дисциплин, представлявших интерес для комплексной градостроительной оценки территории России, для прогнозирования и планирования расселения и градостроительства.

В начале 1990-х годов, на волне «перестройки» в условиях открытости статистических источников, повышения внимания к экологическим проблемам в стране и в мире, впервые обобщаются и публикуются обширные материалы и отчёты об экологическом состоянии территорий регионов и городов, в том числе включающие карты. Это было важно для оценки градостроительных систем. В городах размещались многочисленные источники загрязнения окружающей среды, при отсутствии в то время надлежащей очистки и контроля выбросов, создавались крайне неблагоприятные проблемные ситуации. Экологические факторы ограничивали развитие большинства регионов и городов.

Перед Минстроем России встала задача учёта при планировании расселения, в том числе на «макроуровне», значительно большего количества факторов, сложились предпосылки для существенного расширения информационного поля градостроительной деятельности за счёт картографического обеспечения. В этих условиях появилась необходимость придания картографическому обеспечению более системного, междисциплинарного характера.

Атлас был ориентирован на широкий круг пользователей: специалистов-градостроителей, учёных, педагогов и студентов, управленцев, на заинтересованную общественность. Практическое использование наиболее актуальных научных результатов осуществлялось уже на этапе разработки карт.

«Градостроительный атлас России» разрабатывался впервые, он не имел и не имеет аналогов в зарубежной практике. Главным редактором атласа был Л.В. Хихлуха, заместителем главного редактора - В.Н. Голубев, большой вклад в организацию работ внёс А. С. Кривов. Создание атласа было поручено новой независимой научной организации, созданной при Академии естественных наук Российской Федерации - «Институту геобиосферных исследований». Первый директор, к.г.н. Ю. В. Беляев внёс большой вклад в выполнение работы. Руководителем и ответственным исполнителем темы, автором программы, методологии, методики и содержания ряда карт стала автор данной статьи.
Разработка атласа была сложной в творческом и организационном отношении задачей. Участники междисциплинарного авторского коллектива хорошо понимали актуальность и фундаментальное значение выполняемых работ не только для градостроительства, но и для других, смежных областей.

В создании тематических карт «Градостроительного атласа России» приняли участие д.г-м.н. В. С. Ковалевский, к.г.н. Б. И. Кочуров, д.Г.Н. Б. Б. Прохоров, К.Г.н. Ю.В. Ласис, к.ф-М.н. А. Д. Фридман, К. В. Свирская, Г. М. Львовский, Е. В. Андреева, Т.Н. Денисова, Е. Н. Соцкова и другие. На разработку атласа отводилось три года (без учёта времени на подготовку издания). При создании атласа использовались новейшие теоретические исследования, разработки, опубликованные картографические источники и фондовые материалы «ЦНИИП градостроительства», «ГИПРОГОРа», «СОПСа», «ВНИИСИ», «ИПГ», институтов РАН и прежде всего - «ИГАН», «ИВП», «ИЛ».

К 1992 году «Институтом геобиосферных исследований» была разработана концепция и программа создания атласа с обоснованием целей, задач, методологии и методики составления, с развёрнутой характеристикой содержания и структуры, материалы прошли рецензирование и были утверждены Министерством. Параллельно шла разработка тематических карт, а к 1994 году их было выполнено около трети, но из-за отсутствия финансирования работы по «Градостроительному атласу России» были приостановлены, материалы хранятся в архиве института.

В выполненном объёме материалы «Градостроительного атласа России» объединяют многостороннюю научносправочную информацию по природным и экологическим условиям территории, народо-хозяйственному комплексу и состоянию системы расселения - факторов наиболее значимых для устойчивого развития.

Наработанные материалы и тематические карты позволили выявить на территории России приоритетные проблемы и проблемные ситуации, связанные с радиационной обстановкой, экологией, с экстремальностью климата и неблагоприятными условиями адапции. В составе выполненных карт есть характеристика ландшафтных условий территории с учётом их техногенной нарушенности, гидрологических, гидрогеологических и эколого-гидрогеологических условий расселения и градостроительства.

Получили комплексную оценку некоторые значимые ресурсные факторы территории России - курортно-рекреационные ресурсы, озеленённость территорий городов, урботехногенный потенциал регионов и городов, развитие транспортной инфраструктуры.

Работы по созданию «Градостроительного атласа России», выполненные в начале 90-х годов, можно рассматривать как начальный этап формирования отраслевой информационноаналитической и прогностической базы градостроительной деятельности, которую сегодня можно использовать при формировании перспективных электронных баз данных Минстроя России и Градостроительного кадастра России. 
Современные электронные отраслевые базы данных в большей степени, чем «Градостроительный атлас России», должны стать «хранилищами накопленной информации», в том числе информации 90-х годов.

При разработке методологии и методики составления «Градостроительного атласа России» были использованы литературные источники [8-10], практический опыт ведомственного картографирования ряда министерств и ведомств - МЧС, Госсанэпиднадзора, Роскомгидромета, Минприроды.

При составлении атласа обобщались ведомственные данные и материалы статистической отчётности по стране, регионам и городам, широко использовались экспертные оценки и методы системного анализа. Это традиционный для градостроительных исследований и проектирования инструментарий комплексной оценки территорий, где использовались классификации, выполнялось ранжирование по степени «благоприятности-не благоприятности» для строительства, проводились балльные и вербальные оценки.

Мы разрабатывали «Градостроительный атлас России», надеясь, что он станет не просто систематизированным собранием карт, объединённых общей программой, концепцией и методологией, но что его содержание сможет удовлетворить реальные потребности градостроительной науки, практики и образования в части многофакторного анализа и комплексной (синтетической) оценки перспектив градостроительного развития страны, регионов и городов. Аналогичные задачи стоят перед разработчиками современных отраслевых электронных информационно-прогностических систем. Близость методологии и методики очевидна.

Разработчикам современных отраслевых информационноаналитических систем стратегического планирования пространственного развития, расселения и градостроительства, целесообразно вернуться к опыту работ по «Градостроительному атласу России», который опирался на ряд фундаментальных принципов картографии и создания атласов [8-10]. Им придётся учесть, что принципы системности и комплексности, при работе с градостроительными объектами имеют свои особенности. При работе с различными по своей природе факторами необходимо опираться на принципы «интеграции», решать проблемы сравнимости разнохарактерной информации, выбирать способы её отображения на электронных картах.

\section{Анализ практического опыта разработки «Градострои- тельного атласа России» как отраслевой информаци- онно-аналитической системы}

В соответствии с программой разработки атлас должен был включать 49 карт, сгруппированых по разделам. В наиболее крупном природно-экологическом разделе планировалось 29 тематических карт, в разделе, посвящённом ресурсному потенциалу территории - 17 карт, в разделе градостроительного развития - 3 карты. В каждом разделе предполагалась одна обобщающая (синтетическая) карта.
При составлении атласа было важно обоснование рабочих масштабов: основного и дополнительных, - для оценки проблемных ареалов. Были подготовлены специальные картографические основы в масштабе 1:8 000000 и составлен перечень необходимых фрагментов по проблемным ареалам.

Опыт «Градостроительного атласа России» на основе мелкомасштабных карт ценен и сегодня, поскольку формирование информационной базы пространственного развития на «макроуровне» тоже должно выполняться в мелком масштабе, удобном для рассмотрения на экране компьютера. Использование разработанной в атласе картографической основы в масштабе 1:8 000000 перспективно для электронного картографирования.

Большинство разработанных карт атласа могут использоваться при создании отраслевой информационно-аналитической системы, карты, касающиеся природных и ландшафтноэкологических условий, не потеряли своей актуальности и требуют лишь небольшого уточнения с учётом географических исследований последних 25-и лет.

«Ресурсные карты» (например, курортно-рекреационные ресурсы территории, озеленённость территорий регионов и городов, гидрологические условия расселения градостроительства) могут быть доработаны с использованием новых статистических данных, отраслевой и ведомственной информации по соответствующим направлениям.

При включении в современные информационные системы карты, характеризующие факторы градостроительного развития, например: народно-хозяйственный комплекс регионов и городов, урботехногенный потенциал территории, транспорт - внешний и внутригородской для их современного использования - должны обновляться в большей степени. Например, карта «Развитие городского транспорта» должна быть существенно доработана с учётом автомобилизации и перераспределения объёмов работы между видами городского транспорта. Тоже касается карты «Транспорт России. Основные коммуникации», поскольку в ряде регионов и городов существенно изменились условия транспортного обслуживания, объёмы перевозок, работа пересадочных узлов. При использовании таких карт потребуется учёт новейшей статистической информации и её оценка, исходя из современных подходов и технических возможностей транспортной инфраструктуры.

В целом, в современных информационных системах потребуется повышение комплексности оценок за счёт учёта дополнительных факторов, не являвшихся предметом разработки атласа. Например, в «Градостроительном атласе России» отсутствуют некоторые важные направления комплексной оценки территории, без которых сегодня невозможно представить себе оценку перспектив градостроительного развития.

В соответствии с современными требованиями в информационных градостроительных системах следует учитывать исторические условия расселения и формирования городов, 


агломерационные процессы, предпосылки формирования природных и техногенных катастроф, социальные условия проживания, обеспеченность населения, благоустроенным жильём и «интегральные» оценки комфортности городской среды. Этим вопросом необходимо уделить особое внимание.

К сожалению, небольшое количество публикаций по вопросам пространственного развития, расселения и градостроительства на «макроуровне» - в масштабах страны, отсутствие крупных практических работ по пространственному развитию России, подобных генсхемам расселения, привели к тому, что методология и методика комплексной оценки и прогнозирования на этом уровне за последние 30 лет существенно не продвинулись.

Следует отметить важность формирования информационной базы, основанной на фундаментальных исследованиях независимой от конкретных проектов. Информация по вопросам пространственного развития должна собираться и обобщаться в режиме мониторинга, а не в составе конкретных «схем» или «проектов». Таким образом, необходима постоянно обновляемая информационно-аналитическая и прогностическая база градостроительной деятельности - основа перспективного планирования, проектирования, управления развитием территорий. Основанная на фундаментальных и прикладных исследованиях, постоянно обновляемая и развивающаяся отраслевая информационная база сможет обеспечить Минстрою России, другим заинтересованным министерствам и ведомствам реальную независимость от негосударственных и узковедомственных интересов, сиюминутных целей, задач и идеологии.

По опыту недавней актуализации генплана Москвы хорошо известно, что даже крупнейшая работа может стать неактуальной уже через пять-десять лет после утверждения проекта, при этом огромная информационная и аналитическая часть его может оказаться невостребованной, утратит статус. Фундаментальная информационная и аналитическая база градостроительной отрасли обязательно должна тщательно сохраняться, совершенствоваться для обоснования

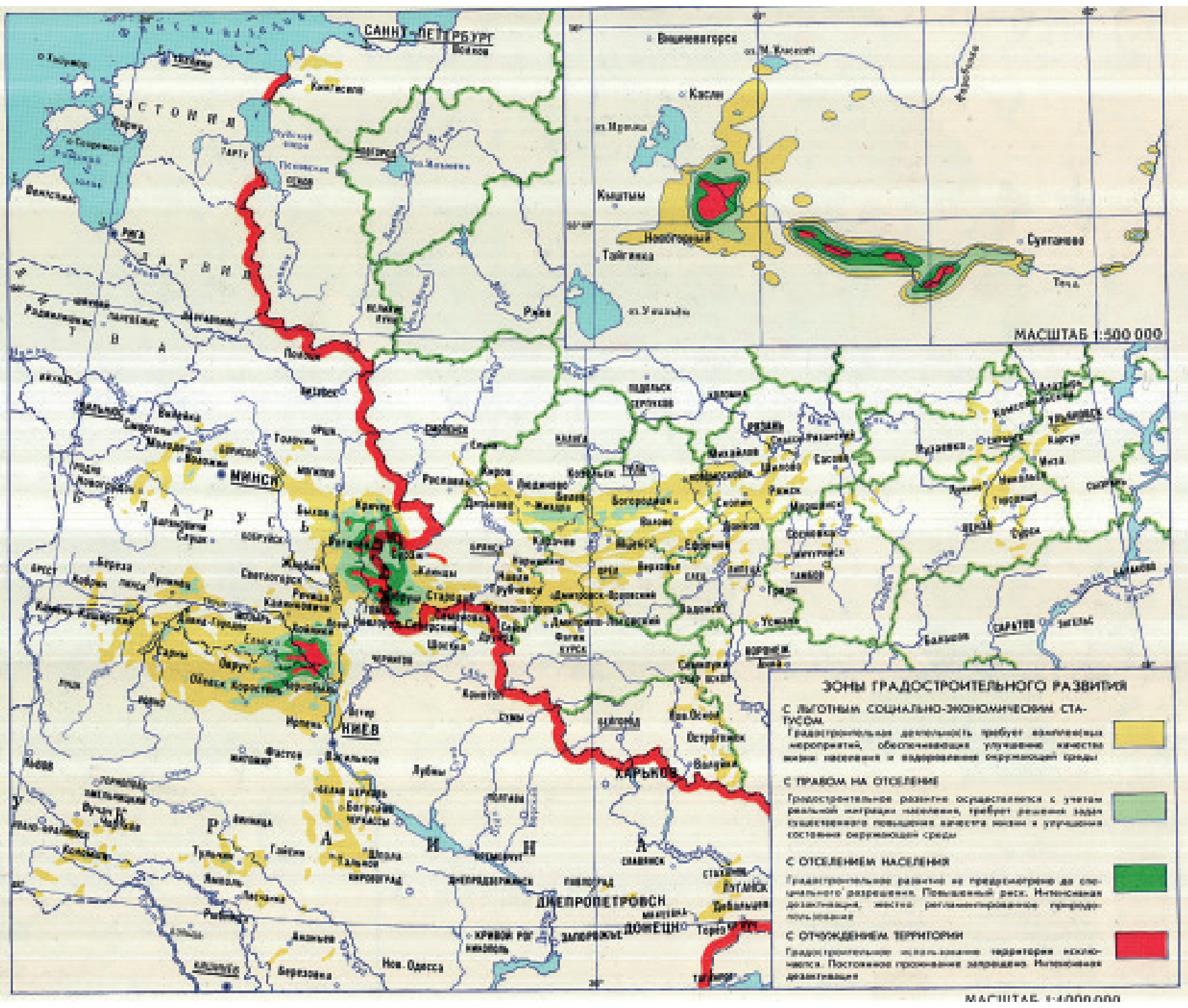

Фрагмент карты радиационной обстановки России (обратная сторона) 
градостроительного развития в масштабах страны, регионов и городов, для планирования развития агломераций, регионов опережающего развития, использоваться в научных исследованиях, в различных видах проектирования, при принятии управленческих решений, а также для подготовки профильных специалистов. Нельзя не учитывать экономический аспект - отраслевая база данных позволяет более эффективно использовать средства, выделяемые на научные обоснования проектных работ, и снижать затраты на предпроектные изыскания.

\section{Актуальность некоторых тематических карт}

К 1994 году «Институтом геобиосферных исследований» было подготовлено 15 тематических карт (факторных и синтетических). При выборе очерёдности разработки карт учитывалась не только информационная преемственность их содержания, но и приоритетность проблем градостроительного развития на ту пору, необходимость детальной разработки некоторых первоочередных задач, исходя из планов развития отрасли.

Одной из первых в атласе была выполнена серия карт по оценке биоклиматической комфортности климата, которые содержали важные для градостроительства оценки условий проживания и адаптации пришлого населения с учётом ландшафтных особенностей территорий и экологических факторов среды, которые отсутствовали в СНиПе по строительной климатологии 2 .

Новой по подходу, ориентированному на задачи расселения и градостроительства, стала серия карт «Транспорт России». Первая карта посвящена внешнему транспорту, вторая - городскому. На карте «0сновные транспортные коммуникации России», изданной пробным тиражом, впервые одновременно были показаны коммуникации и транспортные узлы по четырём видам транспорта, при этом транспортные сети и узлы были классифицированы по мощности и объёмам транспортной работы. Вторая карта по развитию городского транспорта выполнена в разрезе административного деления (по регионам и городам) на основе детальных статистических исследований городского пассажирского транспорта с оценкой перспектив развития. Обе карты после актуализации могут войти в состав отраслевой электронной базы данных.

В методическом и практическом плане представляет интерес синтетическая карта «Урботехногенный потенциал территории России», где оценка территорий регионов и городов была выполнена в разрезе административного деления на основе многофакторного анализа и интеграции разноплановых статистических данных по основным показателям производственного и транспортного комплекса, анализа экологической опасности отраслевой структуры производства, оценки напряжённости экологической ситуации.

${ }^{2}$ СП 131.13330.2012 «Строительная климатология». Актуализированная редакция СНиП 23-01-99* (с Изменениями № 1, 2)
Важно, что, благодаря системной организации работ по созданию атласа и большому количеству наработанной разносторонней информации, у авторов пофакторных карт появилась возможность составить оригинальные синтетические карты с использованием результатов составления других карт атласа. Примером является комплексная карта «Гидрологические, гидрогеологические и эколого-гидрогеологические условия расселения и градостроительства». $0 б$ актуальности проблемы водных ресурсов для градостроительства сегодня говорить не приходится в связи с обострившимися проблемами водообеспеченности и безопасности источников водоснабжения во многих регионах и городах.

Самой актуальной картой на момент создания атласа и обсуждаемой в научных кругах, стала карта «Радиационная обстановка России», которая разрабатывалась как синтетическая, характеризующая природный фон и техногенную обстановку, данные о радиационно-опасных объектах расположенных на территории. Карта создавалась одной из первых в целях обоснования градостроительной политики на территориях, подвергшихся техногенному радиоактивному загрязнению, в том числе в результате аварий на Кыштымской и Чернобыльской АЭС.

При создании карты использовались исключительно опубликованные источники и картографические материалы различного масштаба, при этом впервые природный фон и техногенный уровень загрязнения представлены в одних единицах, что позволило комплексно оценить радиационную обстановку, её реальную опасность. В то время это было важно для выполнения задач, поставленных перед Минстроем России и МЧС России, по переселению жителей, исполнению режимов использования территорий, установленных в зонах поражения и на территориях прилегающих областей России.

Карта уникальна, поскольку ни одна страна мира не проводила детальную авиасъёмку территорий для определения показателей радиационной обстановки территории со сравнением природного фона и техногенного загрязнения территорий.

Аналитический материал всех вышеперечисленных карт и сами карты в генерализированном виде были использованы как раздел «Экологическое состояние урбанизированных территорий», подготовленный Минстроем России для «Государственного доклада о состоянии окружающей среды в РСФСР за 1993 год» Минприроды России 1994 года [11].

\section{Выводы}

1. Исследования по «Градостроительному атласу России», выполненные «Институтом геобиосферных исследований» по заказу Минстроя России в начале 1990-х годов, следует рассматривать как первый опыт создания независимой от конкретных проектов научной базы градостроительной деятельности и проектирования, основанной на комплексном, системном подходе, который сегодня целесообразно использовать для развития научных основ информационно-аналитической 
базы пространственного развития России, стратегического планирования расселения и градостроительной деятельности.

2. В исследованиях, выполненных при разработке атласа, аккумулированы многочисленные, значимые для градостроительства результаты научных исследований в смежных научных дисциплинах: географии, геологии, гидрологии, гидрогеологии, экономики, экологии, геоэкологии, гигиены окружающей среды, и отраслевых технических науках градостроительного и строительного профиля, и подготовлен объёмный научный задел, который при актуализации может быть использован при разработке информационно-аналитической базы Минстроя России.

3. Для создания отраслевой электронной информационноаналитической базы по проблеме пространственного развития представляют интерес методология, программа, структура, состав и содержание карт, выполненные картографические основы масштаба 1:8 000 000, конкретные картографические материалы, а также опыт членов авторского коллектива.

\section{Лuтература}

1. Градостроительная доктрина Российской Федерации / Г.В. Есаулов (рук.), И.Г. Лежава, В.Я. Любовный [и др.]; РАACH. - М. : Экон-информ, 2014. - 30 с.; ISBN 978-5-9506-1154-4

2. Любовный, В. Я. 0 путях разработки градостроительной доктрины/ В.Я. Любовный // Academia. Архитектура и строительство. - 2012. - № 4. - С. 68-72.

3. Белоусов, В.Н. Основные проблемы формирования Градостроительной политики Российской Федерации / В. Н. Белоусов, Д. Ю. Ломакина // Academia. Архитектура и градостроительство. - 2012. - № 4. - С. 73-76.

4. Чистякова С.Б. Использование фундаментальных градостроительных исследований рубежа 80 - начала 90 годов в современной проектной деятельности / С.Б. Чистякова // Градостроительство. - 2019. - № 1 (59). - С. 72-77.

5. Справочник проектировщика. Градостроительство / Гос. ком. по гражд. строительству и архитектуре при Госстрое СССР. Центр. науч.-исслед. и проектный ин-т по градостроительству / Главный редактор В.А. Шквариков - М. : Госстройиздат, 1963. - 367 с. - С. 7-54.

6. Районная планировка. Справочник проектировщика / В.В. Владимиров, Н.И. Наймарк, Г.В. Субботин [и др]. - М. : Стройиздат, 1986. - 325 с:

7. Справочник по картографии / Под ред. Е. И. Халугина. - М. : Недра, 1988. - 430 с.

8. Заруцкая, И.П. Проектирование и составление карт : карты природы / И. П. Заруцкая, Н. В. Красильникова. - М. : Изд-во МГУ, 1989. - 294 С.; ISBN 5-211-00445-0

9. Картографическое обеспечение народнохозяйственной практики : Сб. ст. / АН СССР, Моск. фил. Геогр. о-ва СССР; Отв. ред. Е. П. Аржанов, В. Н. Баюра. - М. : МФГО, 1990. - 119 с.

10. Раздел 12. «Экологическое состояние урбанизированных территорий» // Государственный доклад «0 состоянии окружающей природной среды в Российской Федерации за
1994 год / М-во охраны окружающей среды и природ. ресурсов РФ. - М., 1995.

11. Общая методика составления территориальных комплексных схем охраны окружающей среды городов / ЦНИИП Градостроительства. - М., 1986.

12. Беляева, Е.Л. Социальное картографирование в прогнозной социально-проектной диагностике (К обоснованию создания градостроительного атласа России) / Е.Л. Беляева, Ю.В. Беляев, Ю.В. Ласис // Прогнозное социальное проектирование и город : коллективная монография. - М. : Институт социологии РАН, 1994-1995. - Кн. 3. - С. 415-429 .

13. Беляева, Е.Л. Экология как сфера интеграции междисциплинарных подходов в управлении городом / Е.Л. Беляева // Региональная социология в России : сборник материалов социологических исследований / Отв. ред. В.В.Маркин. Институт социологии РАН. - М. : Экслибрис-Пресс, 2007. - 480 с.; ISBN 978-5-88161-247-4

14. Беляева, Е.Л. 0 задачах экологически ориентированного развития территориальных структур (на примере зоны влияния г. Кемерово) / Е Л. Беляева, Ю.В Беляев // Прогнозирование экономического роста и территориальноотраслевые проблемы народного хозяйства : сб.научн.трудов. - М. : СОПС, 1991.

15. Belyeva, E. Stadtebanatlas Ruslands // Wostok. - 1993. - № 3.

\section{References}

1. Esaulov G.V., Lezhava I.G., Lyubovnyi V.Ya., Yusin G.S., Lomakina D.Yu. Gradostroitel'naya doktrina Rossiiskoi Federatsii [Urban planning doctrine of the Russian Federation]. Moscow, Ekon-inform Publ, 2014, 30 p., ISBN 978-5-9506-1154-4

2. Lyubovnyi, V.Ya. 0 putyakh razrabotki gradostroitel'noi doktriny [0n the ways to develop urban planning doctrine]. Academia. Arkhitektura i stroitel'stvo [Academy. Architecture and construction], 2012, no. 4, pp. 68-72. (In. Russ., abstr. In Engl.)

3. Belousov V.N., Lomakina D.Yu. Osnovnye problemy formirovaniya Gradostroitel'noi politiki Rossiiskoi Federatsii [The main problems of the urban planning policy of the Russian Federation]. Academia. Arkhitektura i stroitel'stvo [Academy. Architecture and construction], 2012, no. 4, pp. 73-76. (In. Russ., abstr. In Engl.)

4. Chistyakova S.B. Ispol'zovanie fundamental'nykh gradostroitel'nykh issledovanii rubezha 80 - nachala 90 godov $\checkmark$ sovremennoi proektnoi deyatel'nosti [The use of fundamental urban research at the turn of the 80 s and early 90 s in modern design activities.]. Gradostroitel'stvo [Urban planning], 2019, no.1 (59), pp. 72-77.

5. Spravochnik proektirovshchika. Gradostroitel'stvo [Designer reference. Urban planning]. V.A. Shkvarikov (ed.). Moscow, Gosstroiizdat Publ., 1963, 367 p., pp. 7-54.

6. Vladimirov V.V., Naimark N.I., Subbotin G.V. [et al.] Raionnaya planirovka. Spravochnik proektirovshchika [District layout. Designer Reference]. Moscow, Stroiizdat Publ., 1986, 325 p. 
7. Spravochnik po kartografii [Cartography Reference]. E. I. Khalugin (ed.). Moscow, Nedra Publ., 1988, 430 p.

8. Zarutskaya I.P., Krasil'nikova N.V. Proektirovanie i sostavlenie kart : karty prirody [Design and Mapping: Nature Maps]. Moscow, MGU Publ., 1989, 294 p.; ISBN 5-211-00445-0

9. Kartograficheskoe obespechenie narodnokhozyaistvennoi praktiki [Cartographic support of national economic practice]: Sb. st. E. P. Arzhanov, V. N. Bayura (eds.). Mosow, MFG0 Publ., 1990, 119 p.

10. Razdel 12. «Ekologicheskoe sostoyanie urbanizirovannykh territorii. Stroitel'nyi kompleks» [Section 12. “The ecological state of urbanized territories. Building complex]. Gosudarstvennyi doklad «0 sostoyanii okruzhayushchei prirodnoi sredy v Rossiiskoi Federatsii za 1994 god [State report "On the state of the environment in the Russian Federation for 1994]. Moscow, 1995.

11. Obshchaya metodika sostavleniya territorial'nykh kompleksnykh skhem okhrany okruzhayushchei sredy gorodov. TsNIIP Gradostroitel'stva, M., 1986.

12. Belyaeva E.L., Belyaev Yu.V., Lasis Yu.V. Sotsial'noe kartografirovanie v prognoznoi sotsial'no-proektnoi diagnostike (K obosnovaniyu sozdaniya gradostroitel'nogo atlasa Rossii)
[Social mapping in forecast social-design diagnostics (0n the rationale for creating an urban atlas of Russia)]. Prognoznoe sotsial'noe proektirovanie $i$ gorod [Predictive social design and the city]. Moscow, Institut sotsiologii RAN Publ., 1994-1995, Book 3, pp. 415-429.

13. Belyaeva E.L. Ekologiya kak sfera integratsii mezhdistsiplinarnykh podkhodov $v$ upravlenii gorodom [Ecology as a sphere of integration of inter-disciplinary approaches in city management]. In Markin V.V. (ed.) Regional'naya sotsiologiya $v$ Rossii [Regional Sociology in Russia]. Moscow, Ekslibris-Press Publ., 2007, 480 p., ISBN 978-5-88161-247-4

14. Belyaeva E.L., Belyaev Yu.V. 0 zadachakh ekologicheski orientirovannogo razvitiya territorial'nykh struktur (na primere zony vliyaniya g. Kemerovo) [0n the tasks of environmentally oriented development of territorial structures (on the example of the influence zone of Kemerovo)]. Prognozirovanie ekonomicheskogo rosta $i$ territorial'no-otraslevye problemy narodnogo khozyaistva [Forecasting economic growth and territorial-sectoral problems of the national economy]: sb.nauchn.trudov. Moscow, SOPS Publ., 1991.

15. Belyeva E. Stadtebanatlas Ruslands. Wostok, no.3

Беляева Елена Львовна (Москва). Кандидат технических наук, советник РААСН, член-корреспондент РАЕН. Директор 000 «Институт геобио-сферных исследований» (113105, Москва, Варшавское шосce, 8. 000 «ИГБИ»). Эл.почта: igbi@yandex.ru.

Belyaeva Elena Lvovna (Moscow). Candidate of Technical Sciences, Advisor to RAACS, Corresponding Member of the Russian Academy of Natural Sciences. Director of the 000 "Institute of Geobiosphere Research" (8 Varshavskoye Shosse, Moscow, 113105. 000 "IGBI"). E-mail: igbi@yandex.ru. 